\title{
Promoção da saúde e ações intersetoriais: foco no Programa Saúde na Escola
}

\author{
Health promotion and intersectorial actions: focus on the School \\ Health Program
}

\author{
Promoción de la salud y acciones intersectoriales: enfoque en el \\ Programa Salud en la Escuela
}

\begin{abstract}
SAÚDE NA ESCOLA: INTERSETORIALIDADE E PROMOÇÃO DA SAÚDE. Silva CS. Rio de Janeiro: Editora Fiocruz; 2019. 170 p. ISBN 978857-541-626-6.
\end{abstract}

doi: 10.1590/0102-311X00001620

O autor, com base em sua expertise e longa experiência na área, nos traz um relato significativo de uma experiência no campo da proposta de consolidação do Programa de Saúde na Escola (PSE) no Município do Rio de Janeiro, Brasil, de 2000-2009, apresentando os modelos, processos e as estratégias utilizadas para tal, à luz dos princípios da promoção da saúde. É importante destacar que a relevância desse relato se dá, dentre outros aspectos, para além da excelência e rigor metodológico da pesquisa, pela longa permanência do autor como gestor da área no Município do Rio de Janeiro, o que certamente contribuiu para que pudesse realizar essa reflexão tão profunda sobre o Programa.

O PSE é uma política de saúde na escola que se propõe a articular e integrar permanentemente os setores saúde e educação com ações que buscam melhorar a qualidade de vida dos alunos de escolas de educação básica, tendo por base ações de prevenção, promoção e atenção à saúde. Busca-se refletir sobre uma prática educativa emancipatória, que transforma saberes existentes, no intuito de fomentar o desenvolvimento da autonomia e da responsabilidade dos indivíduos no cuidado com a saúde 1,2. Segundo Organização Mundial da Saúde (OMS) 3, a educação para a promoção da saúde contém a transmissão de informações relativas às condições sociais, econômicas e ambientais com influência sobre a saúde, bem como condições de risco individual e condutas de risco.

O texto nos permite inferir a atualidade e alinhamento do PSE com a Agenda 2030 para o desenvolvimento sustentável da Organização das Nações Unidas (ONU) 4, no que diz respeito à promoção da saúde, ao crescimento sustentável e à educação inclusiva, em nível de literacia para a saúde em um contexto global de promoção do desenvolvimento sustentável.

A literacia em saúde é o elemento-chave para que as pessoas possam tomar decisões informadas sobre a sua saúde. De acordo com a OMS 3, a literacia em saúde é o conjunto de competências cognitivas e sociais, e a capacidade dos indivíduos para compreenderem e utilizar a informação de forma a promover e manter a saúde.

O texto aponta assim para o papel fundamental dos programas de saúde na escola e da promoção da saúde para o desenvolvimento de cidadãos e sociedades saudáveis, sustentáveis e felizes, razão pela qual contribui para as metas e objetivos definidos pela OMS no que diz respeito ao crescimento sustentável e à educação inclusiva e, para Agenda 2030, para o desenvolvimento sustentável da ONU 5.

A leitura do livro, como a apresentação dessa trajetória e suas etapas, torna-se atraente e convidativa ao leitor, permitindo ao mesmo tempo uma reflexão ao longo do processo, seus desafios e os entraves que surgem. O conteúdo per- 
mite ainda que haja uma pluralidade de leitores, atraindo a atenção de profissionais da saúde, educação, gestores e a comunidade.

No primeiro capítulo, surgem princípios, conceitos, marcos teóricos e práticas da Saúde e Educação, já lançando as bases para a apresentação das escolas promotoras de saúde.

No segundo, apresenta o desenvolvimento histórico da saúde escolar, destacando-se os marcos teóricos conceituais e modelos de PSE no Brasil.

O terceiro capítulo apresenta a trajetória do PSE no Município do Rio de Janeiro, com base numa análise crítica, destacando sucessos e dificuldades para o desenvolvimento do programa. Ao apresentar ao leitor o processo de desenvolvimento do programa, o autor possibilita uma compreensão ampliada do processo, do ponto de vista metodológico, mas também das experiências exitosas ou não, sua eficácia e efetividade.

Finalmente, o quarto capítulo permite ao leitor acompanhar as reflexões sobre a trajetória do PSE no Rio de Janeiro, destacando-se com base nestas reflexões a problematização de situações vividas, com o objetivo de desenvolver aprendizagem valendo-se das mesmas.

Ao introduzir o livro com um capítulo de conceitos e referenciais teóricos, permite a compreensão do leitor sobre as bases fundantes para qual aponta a pesquisa, ao destacar os modelos de educação para saúde nas escolas brasileiras, sua trajetória e desenvolvimento da saúde escolar no Brasil. Já nesse momento, nos apresenta possibilidades de diálogo entre a promoção da saúde e a educação em saúde na escola. Essa contextualização permite ao leitor uma compreensão ampliada de alguns entraves ou limitações que a pesquisa aponta em fases posteriores da mesma, destacando como são problematizadas as relações entre saúde e educação. Como destaca o autor em seu texto: "A organização, a estrutura e o desenvolvimento destas politicas e práticas representam diferentes concepções sobre saúde e educação e a articulação entre esses dois saberes" 6 (p. 1778).

O livro aponta ainda o ambiente escolar como sendo o lócus por excelência para as ações intersetoriais entre educação, saúde e assistência social. A OMS define settings para a saúde como um ambiente de contexto social onde as pessoas estão diariamente engajadas em atividades, sendo que, neste local, fatores pessoais, organizacionais e ambientais estão constantemente interagindo e afetando a saúde e o bem-estar. A aplicação do conceito de settings tem se tornado uma importante ferramenta para a saúde pública. O encorajamento do desenvolvimento sustentado e responsável para a promoção da saúde permite uma abordagem aplicável em diferentes esforços para alcançar os objetivos destacados pela Carta de Ottawa, seja na escola, na comunidade, ou em outros ambientes 7 .

A leitura nos faz questionar sobre o quanto os programas de saúde na escola podem reconhecer os determinantes sociais nos processos de saúde e doença. Em uma revisão integrativa sobre o tema, Lopes et al. 8 não encontraram estudos que abordassem temáticas como meio ambiente ou articulação com as redes sociais, incluindo a comunidade escolar ou o sistema de saúde, na superação das vulnerabilidades enfrentadas por jovens participantes do PSE.

Com relação ao tema intersetorialidade, tão caro e importante nessa produção e que perpassa toda a discussão do livro, destaca-se, no território escolar, o papel do PSE como um importante espaço para a articulação das equipes de atenção básica com os profissionais de educação, proporcionando a sustentabilidade das ações valendose da conformação de redes de responsabilidade compartilhada sobre o território. As ações de promoção da saúde e prevenção de doenças e agravos realizadas no PSE visam a garantir oportunidade a todos os educandos de fazer escolhas mais saudáveis e de serem protagonistas do processo de produção da própria saúde. $\mathrm{O}$ autor nos permite considerar como o programa procura fomentar uma gestão coletiva e participativa das ações, buscando garantir educação e saúde integrais com base na participação dos profissionais, dos educandos e da comunidade.

É relevante destacar que durante a apresentação de todo o processo metodológico pode-se apreender o quão preciosa foi a capacitação em serviço para o alcance dos melhores resultados, mobilizando todos e permitindo ao Programa sua evolução. Isso permite a reflexão sobre a sustentabilidade de um programa como esse, uma vez que parece ser um grande desafio o de formar os/as formadores/as de professores/as, os/ as professores/as e os/as diretores/as das escolas, gestores nestas áreas, e de criar contextos para que o seu desenvolvimento profissional integre a visão de que todos/as eles/as são educadores/as.

No entanto, baseando-se na leitura evidenciamos a carência de articulação entre os setores para o planejamento e execução das ações do Programa, de modo que compromete a intersetorialidade e a integralidade das ações de saúde, 
resultando em ações com foco biológico e alcance limitado na promoção da saúde, prevenção e assistência à saúde. Outros aspectos que foram importantes/relevantes são a formação de professores na área de saúde; o pouco envolvimento dos pais e da comunidade nas tomadas de decisões.

O livro, além da brilhante apresentação da construção do processo do PSE, nos permitindo percorrer a trajetória de cada etapa do Programa, tem o mérito de nos alertar sobre o enorme desafio que ainda temos pela frente, sejamos profissionais da saúde ou da educação, de avançar nas ações intersetoriais buscando articular ações a grupos específicos, como a promoção da saúde no ambiente escolar.

Miriam Ribeiro Calheiros de Sá 1

1 Instituto Nacional de Saúde da Mulher, da Criança e do Adolescente Fernandes Figueira, Fundação Oswaldo Cruz, Rio de Janeiro, Brasil.

calheirosa@uol.com.br

\section{Informação adicional}

ORCID: Miriam Ribeiro Calheiros de Sá (00000002-3972-0377)

1. Figueiredo TAM, Machado VLT, Abreu MMS. A saúde na escola: um breve resgate histórico. Ciênc Saúde Colet 2010; 15:397-402.

2. Silva CS. Escola promotora de saúde: uma nova forma de fazer saúde escolar. In: Lopez FA, Campos Junior D, organizadores. Tratado de pediatria. Barueri: Manole; 2007. p. 289-98.

3. World Health Organization. Health promotion glossary. Geneva: World Health Organization; 1998. (WHO/HPR/HEP/98.1).

4. Organização das Nações Unidas. Transformando nosso mundo: a Agenda 2030 para desenvolvimento sustentável. https://nacoesunidas. org/pos2015/agenda2030/ (acessado em 06/ Jan/2020)

5. World Health Organization. School and youth health: what is a health promoting school? http://www.who.int/school_youth_health/ gshi/hps/en/ (acessado em 06/Jun/2020).

6. Silva CS, Bodstein RCA. Referencial teórico sobre práticas intersetoriais em Promoção da Saúde na Escola. Ciênc Saúde Colet 2016; 21:1777-88.

7. World Health Organization. Healthy settings. http://www.who.int/healthy_settings/en/ (acessado em 06/Jan/2020).

8. Lopes IE, Nogueira JAD, Rocha DG. Eixos de ação do Programa Saúde na Escola e promoção da saúde: revisão integrativa. Saúde Debate 2018; 42:773-89. 